\title{
International Response to Greenhouse Gas Abatement
}

\author{
B. Stephen Labson
}

I

NTERNATIONAL response to the enhanced greenhouse effect is underpinned by the United Nations Framework Convention on Climate Change (FCCC), which came into force on 21 March 1994. It was signed by 154 countries and the European Economic Community (including all OECD countries except Turkey) at the United Nations Conference on the Environment and Development held in Brazil in June 1992.

The FCCC's overall objective is the 'stabilisation of greenhouse gas concentrations in the atmosphere at a level that would prevent dangerous anthropogenic interference with the climate system' (United Nations, 1992:Article 2). Specifically, the Convention calls for the conditional reduction of greenhouse gas emissions to 1990 levels by 2000 . This is to be achieved primarily through measures to be undertaken by developed countries: the so called 'Annex 1' countries. At the first Conference of the Parties held recently in Berlin, it was agreed that the commitment to this objective should be strengthened by requiring Annex I countries to set quantified limitation and reduction objectives, taking into account regional characteristics, the need to maintain strong and sustainable economic growth, and the need for equitable contributions by each of the relevant parties.

Such prescriptive action based on targeted levels of emissions forms an integral part of Australia's National Greenhouse Response Strategy (NGRS), under which an interim planning target has been adopted

to stabilise greenhouse gas emissions (not controlled by the Montreal Protocol on Substances that Deplete the Ozone Layer) based on 1988 levels, by the year 2000 , and to reduce these emissions by 20 per cent by the year 2005 . . . subject to Australia not implementing response measures that would have net adverse economic impacts nationally or on Australia's trade competitiveness, in the absence of similar action by major greenhouse gas producing countries. (Commonwealth of Australia, 1992:8)

While these targets are cast in terms of 'objectives' under the FCCC, and 'as a yardstick against which the implementation of greenhouse response measures can be assessed' under the NGRS, the question remains: do these relatively arbitrary targets

Stephen Labson is Director, Energy Economics, at the Victorian Department of Agriculture, Energy and Minerals. 
provide a useful metric in which to benchmark emissions? That is to say, are such targets based on a rigorous assessment of the science of climate change, its impact on society, and the costs and benefits stemming from emission reduction policies?

\section{The Enhanced Greenhouse Effect: The Basis For Action}

At its most basic level, the greenhouse effect is a reasonably well understood process whereby the earth's atmosphere is warmed through the entrapment of energy by gases, including water vapour, carbon dioxide, methane, nitrous oxide and chlorofluorocarbons. It is also known that the concentration of such 'greenhouse gases' has been gradually increasing since the beginning of the industrial revolution.

What is not currently well understood is the extent to which the concentration of such gases is expected to increase in the future; the effect this will have on the earth's climate and the well-being of its inlabitants; and the extent to which human intervention enhances the greenhouse gas effect. While a great deal has been learned about these matters, a comprehensive understanding of the enhanced greenhouse effect is likely to require a significant leap in our understanding of the dynamics of climatic systems.

In its 1990 report, the Intergovernmental Panel on Climate Change (IPCC) (Houghton et al., 1990) concluded that the global mean surface-air temperature has increased by $0.3^{\circ} \mathrm{C}-0.6^{\circ} \mathrm{C}$ over the past 100 years. Evidence provided from more recent research (summarised in IPCC, 1995) suggests that human activity has had a discernible influence, although the data are insufficient to quantify the impact on climate that is directly attributable to human activity.

Atmospheric scientists regard computer-driven climate-change models as the only feasible means of assessing the impact of increased greenhouse concentrations. The IPCC (1995) has reported a projection based on a mid-range of assumptions regarding population and economic growth, land use, technological change, energy availability and a 'best estimate' of the expected change in global mean surface temperature for a given increase in greenhouse gas concentrations. Under this midrange scenario, it is projected that global temperatures rise by $2^{\circ} \mathrm{C}$ by 2100 . Under this same scenario, the sea level is projected to rise as a result of thermal expansion of the oceans and glacial melting by $50 \mathrm{~cm}$ from the present to 2100 .

Best estimates notwithstanding, projected increases in global warming are still subject to a great deal of uncertainty. ${ }^{1}$ The IPCC (1995) has commented that further work needs to be done: to form more accurate estimates of future emissions and biochemical cycling (the effect of sources and sinks); to represent climate processes in models, especially feedbacks associated with clouds, sea ice and vegetation; and to systematically collect data by which to test modelling results against observation and aid in the quantification of the impact of human activity on climate.

\footnotetext{
1 The IPCC mid-range 'best estimate' projections for mean surface temperature increase and sea level rise are roughly one-third and one-quarter respectively, lower than the same projections formed in 1990. This may offer some information regarding the level of scientific uncertainty that policy-makers are faced with.
} 
More troubling is the fact that it is extremely difficult to quantify the impact of, or to place a cost on, the disruption to physical, social and economic systems for a given level of global warming (see, for example, Schmalensee, 1993). But preliminary estimates surveyed by Nordhaus (1993) suggest that, for the US, an increase in atmospheric temperatures would cause domestic output to fall by between 1 and 1.3 per cent. Nordhaus stresses that the results from the study of a single region in isolation cannot be applied to the world as a whole. Moreover, such studies are likely to overestimate considerably the costs of climate change because they ignore the many ways in which economies, especially their climate-sensitive agricultural sectors, adapt to climatic change through mechanisms such as trade. For example, Rosenzweig and Parry (1994), using a model that links climate, crop yield and trade, found that a doubling of global concentrations of carbon dioxide would cause global output of basic cereals to fall by between zero and 5 per cent under their assumed baseline level of producer adaptation, with the possibility of a slight increase in global production under a more substantial level of adaptation in farming methods.

\section{Carbon Emission Levels in Different Countries}

Carbon dioxide has so far received more attention than other sources of greenhouse gas emissions, principally because of its relative importance (it accounts for roughly 75 per cent of total greenhouse gas emissions stemming from human activity), and partly because emissions of other greenhouse gases are more difficult to estimate. The US is by far the greatest emitter of carbon dioxide, accounting for an estimated 20 per cent of global emissions. Brazil and China also are significant emitters, being responsible respectively for 18.8 and 10.5 per cent of global carbon dioxide emissions. Australia ranks relatively low in terms of the total level of carbon dioxide emissions, contributing an estimated 1.4 per cent, but relatively high in terms of per capita emissions.

Carbon emissions stem primarily from the buming of fossil fuels for energy consumption. For any given level of energy use, a country's emission of carbon from fossil is determined by fuel resource endowment and policy choices. For example, countries which have access to zero or low-emission fuel sources such as hydro and natural gas lave an advantage over countries such as Australia, which relies heavily on low-cost, high-quality coal. Policy choice comes into play with respect to the use of zero-emitting nuclear power. For example, nuclear power contributes 34 per cent to total electricity production in the European Union, 25 per cent in Japan, and 20 per cent in the US. Australia, in contrast, has 110 nuclearpowered generating capability.

The differences in energy consumption levels among countries stem from several underlying factors, above all a region's stage of economic development and the combination of resources and technology unique to individual regions. Economists have observed that energy use closely follows the level of industrialisation within a region. Typically, a developing country's economic activity is based on a relatively larger proportion of energy-intensive industrial processes such as manufacturing and metals smelting. Thus, the rapidly expanding economies of Southeast Asia could 
be expected to increase energy use far above the level expected for the mature economies of the US or European Union. The availability of resources, combined with access to advanced technologies, also has an important bearing on energy use within a region. For example, Japan, which faces relatively high energy prices due to a lack of domestic resources but has access to advanced technologies, has one of the world's lowest energy-GDP ratios. However, it is important to note that this technological efficiency is not a criterion of general economic efficiency. In response to the relative prices it faces, Japan has chosen an efficient set of production plans that use less energy per unit of total output. But it would probably make no economic sense for high-energy-intensity countries such as China or Australia, which are endowed with inexpensive energy resources, to seek to match the energy-GDP ratios of countries such as Japan.

\section{The Cost of Meeting Stabilisation Targets}

Meeting emission targets will have three general effects on a region. First, the fuel mix of the energy sector will change. Coal will tend to be displaced by greater use of low-carbon fuel sources such as oil, natural gas, hydro, nuclear and renewables. Second, an international agreement to stabilise emissions will lead to a decrease in global demand for carbon-intensive energy sources, thereby limiting trade and export revenue from such commodities. Thirdly, the de facto tax implicit in most stabilisation options will serve to reallocate resources away from energy-intensive industries. This change in the sectoral balance of the economy would ultimately have an indirect effect on the level of output throughout the entire economy.

McKibbin et al. (1994) have estimated the cost of meeting several stabilisation scenarios under a phased carbon-tax regime. To return to 1990 emission levels by 2005, Australia would need to decrease emissions by 34 per cent of the level that would have obtained without the policy intervention. The estimated cost to Australia acting in tandem with other OECD countries to stabilise emissions would amount to a loss in GNP of A $\$ 56$ billion by 2005. As a proportion of total GNP, that cost would be considerably greater than that required of the OECD as a whole (and particularly the US, the world's biggest carbon emitter), primarily because Australia's relatively high rate of growth in both population and general economic activity results in a correspondingly higher business-as-usual increase in emissions that would need to be curtailed to meet a stabilisation target. Other factors include Australia's ability to source low-cost energy alternatives and the general ability of the overall economy to adjust to changing relative prices.

It is important to understand that these results are defined in terms of meeting internal stabilisation targets. Developing countries not currently subject to targets are expected to account for by far the largest slare of global emissions of greenhouse gases into the 21st century, rendering regionally based programs largely ineffective in terms of global outcome (ABARE \& Department of Foreign Affairs and Trade, 1995). 


\section{Reducing Greenhouse Gas Emissions: Policy Choices}

Optimal policies to deal with an environmental externality such as the enhanced greenhouse effect are those in which the marginal benefits of the policies are equal to the marginal costs. Nordhaus (1991) has pointed out that the appropriate level of abatement of greenhouse gas emissions depends explicitly on the cost of controlling greenhouse gas emissions, the cost of the damage brought about by the enhanced greenhouse gas effect, and the dynamic interplay of these two factors.

The current scientific and economic literature gives us a preliminary view of some very relevant costs of abatement and damage. Moreover, a new generation of integrated models is being developed to study the interactions between the economy and the environment. But such current modelling efforts should be viewed as a way of focusing attention on proper frameworks for evaluating greenhouse policies, not as a way of quantitatively assessing the appropriate level of emissions and abatement measures.

It seems reasonable to presume that the relatively arbitrary emissions targets that have been endorsed both nationally and internationally are a direct response to scientific and economic uncertainty. But it is hardly comforting to know that the targets correspond to some emission levels found in the latter part of the 20th century. Depending on how one judges the significance of the enhanced greenhouse effect, its cost to society and the cost of abatement, optimal emission levels would probably be either greater or smaller than those observed in the recent past. The issue is further complicated by the relationship between emissions and atmospheric concentration of greenhouse gases. Presumably, our primary concern should be global concentration, but this is seldom directly addressed in policy analysis and development. For example, even if emissions were stabilised, global concentrations of greenlouse gases would continue to increase well into the future. So an arbitrary emission target would seem to be a very crude - indeed useless - yardstick on which to base policy, regardless of the significance of the enhanced greenhouse effect $^{2}$

For a given global target, uniform abatement requirements offer a relatively transparent means by which to achieve global abatement. But it is becoming increasingly well understood that uniform targets are excessively inefficient, mainly because they offer a region little flexibility in allocating its resources vis-à-vis other regions. For example, it might pay Australia, which employs coal-intensive technologies in relatively high-value-added sectors, to encourage other regions to use correspondingly less coal-intensive processes, to the benefit of both.

The FCCC allows parties to the convention to undertake joint action to reduce greenhouse gases. Operationally, this would take the form of measures such as the transfer of energy-efficient technology, equipment and services from developed to developing countries. Such 'joint implementation' measures would mitigate global

\footnotetext{
${ }^{2}$ Feasibility would seem to be an obvious precondition of policy choice. However, Tucker (1994) argues that there has been a 'decoupling of Greenlouse policy and science', whereby governments have endorsed emission reduction targets that are clearly unattainable.
} 
emissions more effectively and economically than would unilateral action by developed countries, since the fairly simple and relatively low-cost technologies that the developing countries could utilise would have a far greater impact on global emissions per dollar spent than would a comparable investment in emission reduction in the developed countries. ${ }^{3}$

Uniform targets are not likely to promote equitable outcomes either. Countries with high levels of growth in population and general economic activity require a continuous increase in energy consumption. Uniform standards, particularly those based on historic emission levels, would impose a relatively costly burden on these high-growth countries. Furthermore, regions have vastly differing resource bases from which to substitute among fuel types. For example, a country such as the US, which has access to a wide range of energy sources including coal, oil, natural gas, hydro and nuclear, will be able to move away from carbon-intensive sources such as coal much more cheaply than a country like Australia, which is more constrained in its fuel choice.

Recognising the problems of efficiency and equity posed by uniform targets, the FCCC states that implementation measures should take into consideration the

situation of Parties, particularly developing country Parties, with economies that are vulnerable to the adverse effects of the implementation of measures to respond to climate change. This applies notably to Parties with economies that are highly dependent on income generated from the production, processing and export, and/or consumption of fossil fuels and associated energy intensive products and/or fossil fuels for which such Parties have serious difficulties switching to alternatives. (United Nations, 1992:Article 4.10)

To balance issues of equity and efficiency, economists have proposed burdensharing mechanisms that apportion abatement costs among countries. For example, the Tasman Institute (1994) has suggested that country targets be developed that give each OECD country the same proportional loss in national income. Altematives might include targets based on equal per capita reductions in emissions, or equal percentage reductions in emissions from baseline levels.

\section{Alternative Measures}

Given the great uncertainty about the costs and benefits of reducing greenhouse gas emissions, 'no regrets' policies have formed a major component of Australia's National Greenhouse Response Strategy. No-regrets policies are typically defined as

\footnotetext{
${ }^{3}$ It is commonly suggested that joint implementation could be developed as a first step toward estallishing an international tradable emissions scheme (see, for example, Bureau of Industry Economics, 1995). This type of scheme is potentially much more eflicient than joint implementation. But distributional concens would probably be significant in view of the quite transparent manner in which wealth would be reallocated under this system.
} 
having no net costs; they arise because the absence of well-functioning markets (whether because of government failure or market failure) makes possible actions that can be implemented at zero net cost to society.

Probably the greatest international scope for such policies lies in the reform of policies that distort energy prices through implicit and explicit taxes and subsidies. Buniaux et al. (1992) find the total value of global energy subsidies (net taxes) to be US $\$ 235$ billion (in 1985 dollars), which is equivalent to US $\$ 45$ per tonne of carbon. They find that the removal of existing distortions in energy markets would lead to a global carbon emissions to be 18 per cent less than otherwise by 2050. Moreover, liberalisation of energy markets would increase GDP (particularly in the non-OECD countries) by promoting the efficient allocation of resources within the broader economy.

Australia's Strategy also develops some first-phase 'insurance' measures to reduce the uncertainty about the impacts of climate change as well as about the viability of responses. These measures involve research and review studies, giving particular attention to energy production, distribution and end use. The objective is to provide a clearer understanding of the emissions mechanisms involved in energy use, the scope for taking no-regrets actions, and our ability to measure emissions and emission reductions. This plased approach reinforces the insurance mechanism by assessing first-phase measures before second-phase measures are formulated and implemented.

\section{Concluding Remarks}

Lack of scientific and economic certainty does not justify policy paralysis: if certainty were a necessary condition for action, it is difficult to imagine how policy-makers could act at all. The point is that the uncertainty inherent in climate-change issues must be factored into the decision-making process in which the risks and associated costs of global warming are balanced against the costs of mitigation strategies. Badly devised strategies present a danger as well. Greenhouse-induced climate change is a global phenomenon and is well addressed only as such. Numerous studies have demonstrated that policies will be largely ineffective if not carried out with the cooperation of developing economies, which are expected to substantially increase emissions well into the 21 st century.

Embracing arbitrary targets that have little apparent relation to these factors would seem to militate against the development of an optinal greenhouse response strategy. It may well be that our current 'yardstick' based on a metric of stabilisation is so imprecise that we would be better off casting it aside for the time being. An international response similar to Australia's phased approach, based on no-regrets measures and well-understood actions such as continued investment in research into climate change, could well be the most appropriate policy. 


\section{References}

ABARE \& Department of Foreign Allairs and Tiade (1995), Global Climate Change: Economic Dimensions of a Cooperative Intenational Policy Response beyond 2000, ABARE, Canberra.

Bureau of Industry Economics (1995), Greenhouse Gas Abatement and Burden Sharing, AGPS, Canberra (Research Report No. 66).

Burniaux, J., J. Martin \& J. Olivaria-Martins (1992), "The Effect of Existing Distortions in Energy Markets on the Costs of Policies to Reduce $\mathrm{CO}_{2}$ Emissions: Evidence from GREEN', OECD Economic Studies 19: 141-65.

Commonwealth of Australia (1992), National Greenhouse Response Strategy, AGPS, Canberra.

Houghton, J., G. Jenkins \& J. Ephraums (eds) (1990), Climate Change: The IPCC Scientific Assessment, Intergovernmental Panel on Climate Change, Cambridge University Press, Cambridge.

Intergovernmental Panel on Climate Change (IPCC) (1995), Summary for Policy Makers of the Contribution on Working Group I to the IPCC Second Assessment Report, IPCC Eleventh Session, Rome, 11-15 December.

McKibbin, W., D. Pearce \& A. Stoeckel (1994), Economic Effects of Reducing Carbon Dioxide Emissions, Centre for Intenational Economics, Canberra.

Nordhaus, W. (1991), 'To Slow or Not to Slow: The Economics of the Greenhouse Effect', Economic Jounzal 101: 920-37.

- (1993), 'Reflections on the Economics of Climate Change', Journal of Economic Perspectives 7(4): $11-25$.

Rosenzweig, C. \& M. Parry (1994), 'Potential Impacts of Climate Change on World Food Supply', Nature 367 (19January): 133-8.

Schmalensee, R. (1993), 'Symposium on Global Climate Change', Journal of Economic Perspectives $7(4): 3-11$.

Tasman Institute (1994), Carbon Dioxide Emissions: Alatement and Burden Sharing in the OECD, Tasman Institute, Melboune.

Tucker, B. (1994), Greenhouse: Facts and Fancies, Institute of Public Affairs, Melbourne (Environmental Backgrounder No. 21).

United Nations (1992), United Nations' Framework Convention on Climate Change, New York

The views stated here are solely the author's. The author would like to acknowledge the helpful comments provided by Brian Tucker and two anonymous referees on a previous draft. 